\title{
Indian Ocean Traffic: Introduction
}

\author{
Lola Sharon Davidson, University of Technology Sydney, and \\ Stephen Muecke, University of New South Wales, guest editors
}

Like the Mediterranean, the Indian Ocean has been a privileged site of cross-cultural contact since ancient times. In this special issue, our contributors track disparate movements of people and ideas around the Indian Ocean region and explore the cultural implications of these contacts and their role in processes that we would come to call transnationalisation and globalisation. The nation is a relatively recent phenomenon anywhere on the globe, and in many countries around the Indian Ocean it was a product of colonisation and independence. So the processes of exchange, migration and cultural influence going on there for many centuries were mostly based on the economics of goods and trade routes, rather than on national identity and state policy.

The motivations and circumstances in which people embarked upon hazardous sea voyages to strange lands were many and varied, though the most common was obviously the hope of material gain. For many people, the unfortunate victims of the slave trade, choice did not enter into it. Others were driven to seek a better life elsewhere by poverty or violence in the lands of their birth, and still others were attracted by the prospect of the large profits to be made in a bustling trading economy. Whatever the motivation, these movements resulted in the creation of heterogeneous, multiethnic, multicultural communities whose various elements often strove to remain in contact with their communities of origin while at the same time necessarily interacting with their immediate neighbours and thereby creating new social and cultural forms. 
Our first three articles concentrate directly on movements of people, ranging from slaves, convicts and indentured workers to prosperous planters, artisans and soldiers. Richard Allen highlights the scale of the Indian Ocean slave trade, often overlooked in comparison with that of the Atlantic. This ancient trade underwent a massive expansion following the entry of the European powers into the Indian Ocean, followed by a contraction as Britain embarked upon its global abolitionist program. However abolitionism affected the form rather than the scale of labour migration, with slave labour being replaced by convict and indentured labour. In time this developed into the modern system of migrant contract labour which continues to play a large role in the economy of the region and, indeed, of the world.

Next, Karin Speedy investigates some of the consequences of the sugar crisis of 1860 which caused thousands of people to abandon Reunion and settle in New Caledonia. Elsewhere Speedy has examined the role of the rich planters who emigrated en masse, taking with them their production equipment, their indentured workers and assorted dependants. In this paper, she concentrates on the many artisans, tradespeople, manual and unskilled workers who also made this move at this time. They were drawn from the ranks of the affranchis (freed slaves) or the petits blancs (impoverished Whites), both of whom faced poverty and social exclusion on Reunion. In moving to New Caledonia they could hope not only for greater prosperity but also for a degree of assimilation into a mixed-race society where social status was determined more by economics than by race.

Anjali Gera Roy focuses attention on the Sikhs who have tended to be confused or conflated with Hindus, Afghans and Muslims in previous discussions of subcontinental migration. Although the Sikh homeland, the Punjab, is distant from the sea, integration into the imperial capitalist economy during the eighteenth and nineteenth centuries prompted rural Sikhs to migrate throughout the Indian Ocean region. Roy argues that the colonial construction of the Sikhs as a martial race facilitated this migration and connects the movements of soldiers and policemen to Shanghai, Hong Kong, the Straits Settlements and Kenya with those of skilled artisans to Mombasa and Uganda. Like Speedy, Roy uses family histories to reveal the specificities of this migration and explore the connections migrants maintained both with their homeland and amongst themselves. 
In the fourth article, Lola Sharon Davidson addresses the pivotal role played by the textile trade both in motivating cultural contact and in creating an area of negotiation for the manifestation of ethnic identity. From ancient times, India was a major exporter of textiles, sitting at the centre of a complex regional network of exchanges which inserted Indian cottons and silks as prestige items into the textile regimes of societies all around the Indian Ocean. Indian textiles were the principal good exchanged both for spices and slaves, an essential element of the wider Indian Ocean trading system. The balance between indigenous and imported textiles, together with the symbolic and aesthetic values manifested through cloth and costume, has permitted the expression of a complex and changing relationship between local and translocal identities in a relentlessly globalising society.

From the exchange of material goods carrying symbolic value, we move to the exchange of ideas, with the next three papers focusing on the circulation of newspapers and literary texts throughout the region and interrogating the way these contribute to changing notions of identity and belonging. Meg Samuelson explores an almost twentyyear long correspondence between the white South African archivist and poet, Marie Kathleen Jeffreys, the first Agent of the colonial Government of India in South Africa, V.S. Srinivasa Sastri, and Sastri’s personal secretary, P. Kodanda Rao. Although Sastri was only resident in South Africa for two years before returning to India, the lifelong correspondence served as a vehicle for the transmission of literary and philosophical texts as well as political newspapers and broadsheets and nurtured a joint mission of championing universalism and opposing the repressive forces of segregation. In directly connecting the intellectual worlds of India and Africa it bypassed the hegemony of the European metropolitan in favour of the recognition of a multiracial Indian Ocean identity.

The role of the journalist in contemporary India is the subject of our next paper. Ursula Rao argues that the rapid commercialisation and professionalisation of the Indian English-language press have affected the reporting of political news by emphasising the role of the journalist as political commentator, encouraging criticism of prevailing forms of vernacular democracy and leadership. At the same time, corporate pressure and the aspirations of India's expanding middle class have led to a positive endorsement of private enterprise. The parallel celebration of consumerism and devaluation of politics is 
the result of a compromise accommodating the critical ethos of a writing profession within a commercialised space.

As the people, the materials and the texts circulate around the Indian Ocean, so too do the stories and the music. Srilata Ravi asks what connects various literary works referencing the Indian Ocean and answers through the image of Banaras in the work of the Mauritian writer and filmmaker, Barlen Pyamootoo. The connections created in the literary universe of Pyamootoo reveal to us the dynamic, multilayered and polyphonic nature of Indian Ocean island culture, the dynamics of creolisation in action.

The issue concludes with two articles examining creolisation from the perspective of a characteristic cultural product, the music of maloya. In October 2009, UNESCO declared the culture of maloya, a genre of song and dance from the island of Reunion, to be an item of international heritage. In his paper, Stephen Muecke investigates what UNESCO thinks it is protecting and why it might have decided to do so. He points out that this formal endorsement of Creole culture coincides with an upsurge in Creole nationalism, a political stance exemplified by the manifesto of Françoise Vergès and Carpanin Marimoutou with which our issue concludes. The text by Vergès and Marimoutou is translated from French and provides a valuable counterpoint to the Anglophone discourse with which we are more usually familiar. It offers an interpretation of creolisation from the perspective of Reunion as an Indian Ocean island. Opposing the political and cultural hegemony of France, it seeks a recognition of the island's past that can support a celebration of Reunion's cultural and historic connections with other Indian Ocean societies. In this, it joins forces with various anticolonial and transnational movements that are increasingly evident in the Indian Ocean.

In this special issue on the Indian Ocean, the contributors have sought to elucidate just a few of the multifarious, complex relationships that connect the many widely different human societies that inhabit the Ocean's shores. Dissolved by its waters, swirled by its currents, driven back and forth by its monsoon winds, identities unravel and are woven afresh in a continuing process of creative communication. 